\title{
Review \\ Translating co-stimulation blockade into clinical practice
}

Rene Westhovens and Patrick Verschueren

Department of Rheumatology, University Hospitals KU Leuven, Herestraat, B-3000 Leuven, Belgium

Corresponding author: Rene Westhovens, rene.westhovens@uz.kuleuven.be

Published: 15 October 2008

This article is online at http://arthritis-research.com/supplements/10/S1/S4

(c) 2008 BioMed Central Ltd
Arthritis Research \& Therapy 2008, 10(Suppl 1):S4 (doi:10.1186/ar2415)

rituximab has a different treatment schedule (intermittent) and a different response profile, characterized by more gradual onset of beneficial effect, beginning only a few months after infusion. Additional data regarding the optimal timing of retreatment are needed, and there remain unanswered questions regarding the long-term safety and risks associated with use of other biologicals after rituximab has failed $[3,4]$. In systemic lupus erythematosus (classically considered a B-celldriven disease), B-cell directed therapies are being trialled, and the first promising clinical results have been published [5]. B-cell targeted therapies are also being tested in other systemic diseases, such as primary Sjögren's syndrome [6].

Although initial attempts to target the $T$ cell were not particularly successful [7], co-stimulation blockade is very promising in the treatment of several diseases that are driven by an activated adaptive immune system. Co-stimulation blockade was first clinically tested in the treatment of psoriasis [8], but patients with RA were the first to benefit from the advent of abatacept, which is the first co-stimulation blocker $[9,10]$. Experience with abatacept in RA is growing thanks to open-label extensions of clinical trials [11], but published data from routine practice and patient registries are currently lacking. Trials of abatacept in systemic lupus erythematosus, psoriatic arthritis and Crohn's disease are underway.

Biologicals are often compared solely based on their level of efficacy in RA, by measuring Disease Activity Score and American College of Rheumatology (ACR) responses at fixed time points, without considering differences in mechanisms of action, in efficacy and safety profiles, and in administration, or patient preferences and patient reported outcomes. A biological is a biological. However, in recent years we have learned that efalizumab [12] is effective in plaque psoriasis but not in psoriatic arthritis, that etanercept is effective in RA and spondyloarthropathy but not in Crohn's disease [13], and that etanercept might induce sarcoidosis [14]. From these examples, it is clear that the different modes of action of

$\mathrm{ACR}=$ American College of Rheumatology $\mathrm{RA}=$ rheumatoid arthritis; $\mathrm{RF}=$ rheumatoid factor; $\mathrm{TNF}=$ tumor necrosis factor. 
individual biologicals have important implications for their use in routine clinicial practice.

\section{The need for biologicals with a different mode of action in rheumatoid arthritis}

TNF blockers have altered the clinical evolution of many previously refractory patients, but based on findings from registries and cohort studies it is clear that many patients still exhibit insufficient response, lose their initial response, or have to stop treatment because of specific side effects. Until now, in case of failure of a TNF blocker, a common strategy has been to try a second TNF blocker. However, careful analysis of patient registries shows that if a first TNF blocker is discontinued for efficacy or safety reasons, then the reason for failure of a second TNF blocker is likely to be the same as that for the first anti-TNF treatment [15]. In a recent Swiss observational study [16], it was suggested that a drug with a different mechanism of action, such as rituximab, has greater potential benefit in this setting, but a corroborating randomized trial is lacking. Although the increasing number of therapeutic options is good news for patients, the rheumatology community is increasingly confronted with the dilemma of which treatment to use in which situation and in which order. The question also arises of how to monitor and evaluate these agents in routine practice.

With respect to general efficacy, no major differences are expected based on the findings of reported clinical trials. (The ATTAIN [Abatacept Trial in Treatment of Anti-TNF INadequate responders] [10] and REFLEX [Randomized Evaluation of Long-Term Efficacy of Rituximab] [17] trials reported similar ACR responses for abatacept and rituximab, respectively.) However, head to head clinical trials comparing different biologicals are lacking. The only currently available blinded randomized trial was not powered to identify a difference between abatacept and infliximab [18], but it confirmed the existence of small differences in efficacy profiles and safety, suggesting that not all biologicals are the same. Differences in clinical effectiveness are to be expected when these agents are incorporated in different therapeutic strategies and administered to patients with different disease characteristics, risk profiles, and co-morbidities. Also, patient preferences are increasingly expected to play a role in decision making in the future. Finally, the quality of care programs in which these highly effective drugs are to be used could be at least as important as their intrinsic level of efficacy.

The focus of this review is the importance of high-quality care in RA and how current and future therapeutic options will fulfil the changing needs of patients, placing special emphasis on co-stimulation blockade. Our expectations from new treatments can be summarized as a combination of good efficacy and effectiveness, short-term and long-term safety, and improvement in functionality and quality of life, and all of this at an acceptable cost and for as many patients as possible.

\section{Efficacy and effectiveness of treatment for rheumatoid arthritis with co-stimulation blockade}

The efficacy of abatacept has been demonstrated in large, properly designed trials in patients refractory to methotrexate [9] and to anti-TNF treatment [10]. Comparison of efficacy between abatacept and other biologicals is not possible because no good head to head comparisons are available, and the currently reported differences in efficacy between biologicals are mainly accounted for by the previous refractory state of patients, specific patient characteristics and specific co-morbidities.

In ATTAIN 25\% of patients were rheumatoid factor (RF) negative, and these patients' responses to abatacept treatment were no different from those of RF-positive patients. Not many RF-negative patients have been evaluated in rituximab trials, but in a recent study conducted by Popa and coworkers [19], after 7 years follow up four out of five RF-negative patients were found to be nonresponders. The impact of patient characteristics on treatment efficacy needs to be analyzed more systematically in future studies, especially in registries.

Effectiveness in daily practice might differ between biologicals because of their different response profiles (speed of response, stability of response, and so on). TNF blockers, especially infliximab, have a very rapid effect (which is in the interests of patients) but after a while the response sometimes diminishes, and questions arise regarding dosing and treatment frequency, especially for infliximab [20]. A flare of arthritis in a patient receiving infliximab a few days before a newly scheduled infusion is not appreciated and might influence the effectiveness of treatment. The lack of information in rituximab-treated patients regarding the optimal timing of retreatment led to the requirement for a flare (defined by a rise in the Disease Activity Score above 3.2) in the Belgian reimbursement criteria for retreatment. Having to wait for a flare before retreatment is allowed can hardly be considered patient friendly.

On the other hand, continuous monthly dosing of abatacept is apparently associated with a stable response, and the patient dropout rates from the extension trials are rather low (high retention rates) [21]. Stable disease control might be a patient-preferred outcome that requires more study in the future. In certain respects the response profile of TNF blockers resembles the effect of corticosteroids, with rapid onset but also rapid loss of effect as soon as treatment is interrupted, which is in contrast to the gradual but more longlasting effect of B-cell-depleting therapies or co-stimulation blockade. Our experience with abatacept is that it elicits a very stable response, and a flare is rarely seen even when an infusion is postponed for infection or surgery. This also suggests that in future studies the infusion interval for longterm treatment should be formally determined. 
One might argue that co-stimulation blockade is not as fastacting as TNF blockade. On the other hand, starting a bridging therapy with a short course of steroids together with abatacept is a cheap and effective strategy to overcome this temporary disadvantage, provided that steroids do not influence the efficacy of co-stimulation blockade. Also, when analyzing in detail the speed of response to abatacept, one may observe a statistically significant effect in certain patient outcomes (such as fatigue) even after 4 weeks [22], which might positively influence patient adherence to therapy.

The specific mechanism of action of co-stimulation blockade, being more upstream in the immunological cascade as compared with TNF blockade, could theoretically lead to an even more pronounced effect when the agent is used very early in a disease. Post-hoc subgroup analyses of AIM have demonstrated greater remission rates in patients with early disease $(<2$ years) compared with longer standing disease ( $>10$ years) [23]. The results of a trial of abatacept in early RA are expected at the end of 2008.

In addition, a formal trial studying the effect of discontinuing treatment once remission is achieved or after a certain period of time might be interesting, in the light of the different mechanisms of action of co-stimulation blockers as compared with TNF-blocking agents. A recent trial in undifferentiated arthritis with poor prognosis patients (namely, those positive for cyclic citrullinated protein) failed to identify an effect of a short course of anti-TNF treatment in delaying the onset of RA (in terms of fulfilling ACR criteria) [24]. In contrast, a similar explorative study of abatacept indicated that this agent appears able to delay the onset of RA to some extent [25]; this needs further investigation.

The first and most impressive message from the trials of TNF blockade was the complete arrest of radiographic progression, which had never previously been observed with any RA treatment. Data on abatacept indicate a decrease in radiographic progression during the first year, without complete arrest but with a further decrease in year 2 [26], illustrating a different efficacy profile as compared with TNF blockers. This is an important finding with clinical implications for future treatment decisions in routine practice. However, in view of the more gradual effect of abatacept, in clinical practice many rheumatologists might add a short bridging therapy with steroids, which could have a major impact on the kinetics of response and, therefore, future radiographic progression, especially in early RA. Moreover, we must await data on radiographic progression in the early RA abatacept trial, because these might reveal differences from findings in established RA. Recent experimental findings suggest a specific effect of cytotoxic T-lymphocyte antigen 4 on bone, independent from TNF- $\alpha$; it would be interesting to investigate this in the clinical setting, given the possible implications for long-term disease control [27].
Theoretically, one could consider combining different targeted therapies in order to achieve a better response. However, combinations of different biologicals, such as TNF blockers and interleukin-1 receptor antagonists, do not appear to increase efficacy [28] and result in more side effects, as is the case when abatacept is combined with TNF blockade [29].

\section{Improvement in functionality and quality of life with co-stimulation blockade in patients with rheumatoid arthritis}

One might expect that all improvements in disease activity might be associated with improved functionality and quality of life, and that, as such, all biologicals would have similar effects. This might be true to some extent, because similar improvements in 36-item Short Form are found for many agents [22,30]. An important issue is whether measures such as 36-item Short Form are sensitive enough to detect specific and subtle differences between biologicals in patient-centered outcomes. Patient-centered outcomes might be influenced by the stability of disease control, the route of administration (subcutaneous versus intravenous, length of perfusion time), risk for infusion reactions (up to $30 \%$ in rituximab trials with need for pretreatment versus a few percent in abatacept trials), or perhaps other factors of importance to patients that need more study. An example of an issue that should be studied in greater detail is sleep. TNF blockade might have a direct central effect on sleep [31,32]. Steroids are known for their central stimulatory effect. The first studies with abatacept suggest a beneficial effect on sleep [33]. More detailed studies specifically comparing different treatment options head to head with respect to such specific patient-centered outcomes would be welcome in the future because of their relevance to daily care.

\section{Safety of co-stimulation blockade and implications for daily practice in patients with rheumatoid arthritis}

A safety update on abatacept [34] was recently reported and suggested a different safety profile as compared with infliximab and rituximab regarding infusion reactions, which might influence patients' preferences and improve treatment effectiveness in the long run.

The lack of de novo development of antinuclear antibodies and DNA antibodies with abatacept, in contrast to TNF blockers [18], certainly deserves further attention and might suggest a role for abatacept (or rituximab) in patients who develop a clinical picture with newly occurring autoimmune features, rather than switching to a second or third TNF blocker. One might consider treating patients with heart failure preferentially with abatacept instead of a TNF blocker, and patients with a history of or an active associated B-cell lymphoma might be good candidates for anti-B-cell therapy.

Increased infection rates have been reported with all biologicals, but rates are difficult to compare between drugs 
because there are no sufficient head to head comparisons. Nevertheless, apart from different patient characteristics and possible co-morbidities, the treatment choice as such might have an influence on infection rates, as is suggested by the ATTEST (Abatacept or infliximab versus placebo, a Trial for Tolerability, Efficacy and Safety in Treating RA) data [18] and by the findings of a recent meta-analysis that compared anakinra with abatacept and rituximab [35]. All of these findings might play roles in future therapeutic decisions in specific circumstances. The different mode of action of abatacept relative to TNF-blockade means that the former has a lesser impact on natural mechanisms of defense against tuberculosis [18] - a finding that has received support from a recent animal model study [36]; this property might have a bearing on future decision making.

Little is known about differences in immune profiles after long-term treatment with specific biologicals. Long-term rituximab treatment appears to be associated with some persisting decline in immune globulin titers and a certain degree of lasting B-cell depletion [19]. The clinical relevance of these findings requires further study. Reports on immune states after long-term abatacept treatment are not available, but based on findings reported to date no cell depletion or decrease in immunoglobulin levels are expected with this agent.

In summary, safety profiles appear to differ between biologicals. Together with the pretreatment evaluation of specific risk factors, these differences might influence treatment choices in daily practice.

\section{Key messages}

- The different modes of action of individual biologicals have important implications for their use in clinical practice.

- Differences in effectiveness are to be expected with the incorporation of biologicals into different therapeutic strategies and with their use in patients who differ in terms of other disease characteristics, risk profiles and co-morbidities.

- The quality of care programs in which these highly effective drugs are to be used could be at least as important as their intrinsic level of efficacy.

- The efficacy of abatacept, as measured using classical outcome measures, appears similar to that of anti-TNF agents and rituximab.

- Co-stimulation blockade might in certain circumstances be more appropriate than other targeted therapies

\section{Conclusion}

Newer drugs with different modes of action, such as rituximab and abatacept, might be attractive alternatives in patients refractory to a TNF blocker. While at first glance efficacy of all drugs might look the same, different efficacy (speed and stability of response) and safety (infection rates, infusion reactions) profiles are observed. Also, effectiveness in daily practice might differ as a result of patient preferences. Further study is needed in daily practice to compare different treatment strategies, focussing on global effectiveness.

\section{Competing interests}

RW is a consultant for Schering Plough Belgium and for Bristol-Myers Squibb. PV is a consultant for Schering Plough Belgium.

\section{Acknowledgements}

This article is published as part of Arthritis Research \& Therapy Volume 10 Supplement 1, 2008: Co-stimulation blockade: from bench to bedside. The full contents of the supplement are available online at http://arthritis-research.com/supplements/10/S1.

Publication of this supplement has been sponsored by Bristol-Myers Squibb Company.

\section{References}

1. Weinblatt ME: Will our current success in treating rheumatoid arthritis hinder new drug development? That is the question! Ann Rheum Dis 2005, 64:1529-1531.

2. Furst DE, Breedveld FC, Kalden JR, Smolen JS, Burmester GR, Sieper J, Emery P, Keystone EC, Schiff MH, Mease P, van Riel PL, Fleischmann $\mathrm{R}$, Weisman $\mathrm{MH}$, Weinblatt ME: Updated consensus statement on biological agents for the treatment of rheumatic diseases. Ann Rheum Dis 2007, 3(suppl):iii2-22.

3. Frampton JE, Scott LJ: Rituximab in rheumatoid arthritis. BioDrugs 2007, 21:333-341. Discussion 342.

4. Kavanaugh AF: B cell targeted therapies: safety considerations. J Rheumatol 2006, 77:18-23.

5. Tieng AT, Peeva E: B-cell-directed therapies in systemic lupus erythematosus. Semin Arthritis Rheum 2008 [Epub ahead of print].

6. Steinfeld SD, Tant L, Burmester GR, Teoh NK, Wegener WA Goldenberg DM, Pradier O: Epratuzumab (humanised antiCD22 antibody) in primary Sjögren's syndrome: an open-label phase I/II study. Arthritis Res Ther 2006, 8:R129.

7. van der Lubbe PA, Dijkmans BA, Markusse HM, Nässander U, Breedveld FC: A randomized, double-blind, placebo-controlled study of CD4 monoclonal antibody therapy in early rheumatoid arthritis. Arthritis Rheum 1995, 38:1097-1106.

8. Abrams JR, Lebwohl MG, Guzzo CA, Jegasothy BV, Goldfarb MT Goffe BS, Menter A, Lowe NJ, Krueger G, Brown MJ, Weiner RS, Birkhofer MJ, Warner GL, Berry KK, Linsley PS, Krueger JG, Ochs HD, Kelley SL, Kang S: CTLA4Ig-mediated blockade of T-cell costimulation in patients with psoriasis vulgaris. J Clin Invest 1999, 103:1243-1252.

9. Kremer JM, Genant HK, Moreland LW, Russell AS, Emery P, Abud-Mendoza C, Szechinski J, Li T, Ge Z, Becker JC, Westhovens R: Effects of abatacept in patients with methotrexateresistant active rheumatoid arthritis: a randomized trial. Ann Intern Med 2006, 144:865-876.

10. Genovese MC, Becker JC, Schiff $M$, Luggen $M$, Sherrer $Y$, Kremer J, Birbara C, Box J, Natarajan K, Nuamah I, Li T, Aranda R, Hagerty DT, Dougados M: Abatacept for rheumatoid arthritis refractory to tumor necrosis factor alpha inhibition. $N$ Engl $J$ Med 2005, 353:1114-1123.

11. Genovese MC, Schiff M, Luggen M, Becker JC, Aranda R, Teng J: Efficacy and safety of the selective co-stimulation modulator abatacept following 2 years of treatment in patients with rheumatoid arthritis and an inadequate response to anti-tumour 
necrosis factor therapy. Ann Rheum Dis 2008, 67:547-554.

12. Papp KA, Caro I, Leung HM, Garovoy M, Mease PJ: Efalizumab for the treatment of psoriatic arthritis. J Cutan Med Surg 2007, 11:57-66.

13. Wallis RS, Ehlers S: Tumor necrosis factor and granuloma biology: explaining the differential infection risk of etanercept and infliximab. Semin Arthritis Rheum 2005, 34(suppl 1):34-38.

14. Verschueren K, Van Essche E, Verschueren P, Taelman V, Westhovens R: Development of sarcoidosis in etanercept-treated rheumatoid arthritis patients. Clin Rheumatol 2007, 26:19691971.

15. Hyrich KL, Lunt M, Watson KD, Symmons DP, Silman AJ, British Society for Rheumatology Biologics Register: Outcomes after switching from one anti-tumor necrosis factor alpha agent to a second anti-tumor necrosis factor alpha agent in patients with rheumatoid arthritis: results from a large UK national cohort study. Arthritis Rheum 2007, 56:13-20.

16. Finckh A, Ciurea A, Brulhart L, Kyburz D, Möller B, Dehler S, Revaz S, Dudler J, Gabay C, Physicians of the Swiss Clinical Quality Management Program for Rheumatoid Arthritis: B cell depletion may be more effective than switching to an alternative anti-tumor necrosis factor agent in rheumatoid arthritis patients with inadequate response to anti-tumor necrosis factor agents. Arthritis Rheum 2007, 56:1417-1423.

17. Cohen SB, Emery P, Greenwald MW, Dougados M, Furie RA, Genovese MC, Keystone EC, Loveless JE, Burmester GR, Cravets MW, Hessey EW, Shaw T, Totoritis MC, REFLEX Trial Group: Rituximab for rheumatoid arthritis refractory to antitumor necrosis factor therapy: results of a multicenter, randomized, double-blind, placebo-controlled, phase III trial evaluating primary efficacy and safety at twenty-four weeks. Arthritis Rheum 2006, 54:2793-2806.

18. Schiff M, Keiserman M, Codding C, Songcharoen S, Berman A, Nayiager S: Efficacy and safety of abatacept or infliximab versus placebo in ATTEST: a phase III, multicenter, randomized, double-blind, placebo-controlled study in patients with rheumatoid arthritis and an inadequate response to methotrexate. Ann Rheum Dis 2007 [Epub ahead of print].

19. Popa C, Leandro MJ, Cambridge G, Edwards JC: Repeated B lymphocyte depletion with rituximab in rheumatoid arthritis over 7 yrs. Rheumatology (Oxford) 2007, 46:626-630.

20. Rahman MU, Strusberg I, Geusens P, Berman A, Yocum D, Baker D, Wagner C, Han J, Westhovens R: Double-blinded infliximab dose escalation in patients with rheumatoid arthritis. Ann Rheum Dis 2007, 66:1233-1238.

21. Westhovens R, Kremer J, Moreland L, Emery P, Russell A, Li T, Aranda R, Becker J-C, Joshi C, Dougados M: Sustained efficacy and safety of abatacept in rheumatoid arthritis patients receiving background methotrexate through 5 years of treatment [abstract]. Arthritis Rheum 2007, 56(suppl):S395

22. Westhovens R, Cole JC, Li T, Martin M, Maclean R, Lin P, Blaisdell B, Wallenstein GV, Aranda R, Sherrer Y: Improved healthrelated quality of life for rheumatoid arthritis patients treated with abatacept who have inadequate response to anti-TNF therapy in a double-blind, placebo-controlled, multicentre randomized clinical trial. Rheumatology (Oxford) 2006, 45: 1238-1246.

23. Yazici Y, Moniz Reed D, Klem C, Rosenblatt LC, Wu G, Kremer J: Biologic naïve early rheumatoid arthritis (RA) patients treated with abatacept achieve greater disease remission compared to RA patients with long standing disease, with nearly half of early RA patients in DAS28 remission at 3 years. Ann Rheum Dis 2008, 67(Suppl II):126.

24. Saleem B, Mackie $S$, Quinn $M$, Nizam $S$, Hensor $E$, Jarrett $S$, Conaghan PG, Emery P: Does the use of TNF antagonist therapy in poor prognosis, undifferentiated arthritis prevent progression to rheumatoid arthritis? Ann Rheum Dis 2008 [Epub ahead of print].

25. Emery $P$, Durez $P$, Dougados $M$, Becker JC, Vratsanos G, Mitra $P$, Overfield S, Qi K, Westhovens R: Efficacy of abatacept in delaying the development of rheumatoid arthritis (RA) in adult patients with undifferentiated inflammatory arthritis at high risk of developing RA. Ann Rheum Dis 2008, 67(Suppl II): 89 .

26. Genant HK, Peterfy CG, Westhovens R, Becker JC, Aranda R, Vratsanos G, Teng J, Kremer JM: Abatacept inhibits structural damage progression in rheumatoid arthritis: results from the long-term extension of the AIM trial. Ann Rheum Dis 2007 [Epub ahead of print].

27. Axmann R, Herman S, Zaiss M, Franz S, Polzer K, Zwerina J: CTLA-4 directly inhibits osteoclast formation. Ann Rheum Dis 2008 [Epub ahead of print].

28. Genovese MC, Cohen S, Moreland L, Lium D, Robbins S, Newmark R, Bekker P: 20000223 Study Group: Combination therapy with etanercept and anakinra in the treatment of patients with rheumatoid arthritis who have been treated unsuccessfully with methotrexate. Arthritis Rheum 2004, 50: $1412-1419$

29. Weinblatt M, Combe B, Covucci A, Aranda R, Becker JC, Keystone E: Safety of the selective costimulation modulator abatacept in rheumatoid arthritis patients receiving background biologic and nonbiologic disease-modifying antirheumatic drugs: A one-year randomized, placebo-controlled study. Arthritis Rheum 2006, 54:2807-2816.

30. Han C, Smolen JS, Kavanaugh A, van der Heijde D, Braun J, Westhovens R: The impact of infliximab treatment on quality of life in patients with inflammatory rheumatic diseases [abstract]. Arthritis Res Ther 2007, 9:R103.

31. Zamarrón C, Maceiras F, González J, Gómez-Reino JJ: Worsening of obstructive sleep apnoeas in a patient with rheumatoid arthritis treated with anti-tumor necrosis factor. Respir Med 2004, 98:123-125.

32. Zamarrón C, Maceiras F, Mera A, Gómez-Reino JJ: Effect of the first infliximab infusion on sleep and alertness in patients with active rheumatoid arthritis. Ann Rheum Dis 2004, 63:8890.

33. Wells G, Li T, Maxwell L, Maclean R, Tugwell P: Responsiveness of patient reported outcomes including fatigue, sleep quality, activity limitation, and quality of life following treatment with abatacept for rheumatoid arthritis. Ann Rheum Dis 2008, 67: 260-265.

34. Sibilia J, Westhovens R: Safety of T-cell co-stimulation modulation with abatacept in patients with rheumatoid arthritis.Clin Exp Rheumato/ 2007, 25(suppl 46):S46-S56.

35. Salliot C, Dougados M, Gossec L: Risk of serious infections during rituximab, abatacept and anakinra therapies for rheumatoid arthritis: meta-analyses of randomized placebocontrolled trials. Ann Rheum Dis 2008 [Epub ahead of print].

36. Bigbee CL, Gonchoroff DG, Vratsanos G, Nadler SG, Haggerty $\mathrm{HG}$, Flynn JL: Abatacept treatment does not exacerbate chronic Mycobacterium tuberculosis infection in mice. Arthritis Rheum 2007, 56:2557-2565. 